\title{
PHOTOTHERAPY IN THE TREATMENT OF DIABETIC FOOT - A PRELIMINARY STUDY
}

\author{
Zbigniew Mikołajczyk', Iwona Nowak', Andrzej Kawiński², Michał Mik² \\ 1 Lodz University of Technology, Faculty of Material Technologies and Textile Design, Poland \\ 2 Medical University of Lodz, Poland \\ *Corresponding author. E-mail: zbigniew.mikolajczyk@p.lodz.pl
}

\begin{abstract}
:
The first part of the publication presents a substantively insightful literature study on the essence and effects of light waves on wound healing in living organisms, including the use of phototherapy in the treatment of the diabetic foot. A knitted textile dressing was designed and manufactured for phototherapy of patients with diabetes suffering from diabetic foot syndrome (DFS). The proposed solution is intended for the treatment of dermal tissues within the patient's foot affected because of diabetic disease at an early stage. Thus, the use of a knitted dressing with incorporated fiber optic structures and powered by a semiconductor laser emitting a $405 \mathrm{~nm}$ light wave from its entire surface would prevent further anomalies of the patient's tissues and help to avoid surgical intervention.
\end{abstract}

\section{Keywords:}

Phototherapy, fiber optics, knitted dressing, diabetes, diabetic foot syndrome

\section{Introduction}

Type 2 diabetes mellitus is the most common disease in modern society and the number of people suffering from this disease is increasing dramatically every year.

Over 422 million subjects worldwide have been estimated to suffer from diabetes, including approximately $25-30 \%$ of people whose disease has not yet been diagnosed. In Europe, up to 59.8 million people may be affected by diabetes. About 1.6 million people die from diabetes all over the world every year. According to the data of the Central Statistical Office in Poland, nearly 3 million people, which is approximately $8.8 \%$ of the adult population, suffer from diabetes, and $20 \%$ of them are unaware of it. Among subjects $>70$ years of age, as many as $20 \%$ have diabetes. Type 2 diabetes accounts for $>80-90 \%$ of all cases of diabetes [1-2].

If diabetes is left untreated or improperly treated, it carries a risk of several complications such as diabetic retinopathy, diabetic nephropathy, ketoacidosis, lactic acidosis, cardiovascular disorders, renal complications, and the most common complication referred to as diabetic foot syndrome (DFS) [1-2].

DFS is a condition involving damage to the nerves and blood vessels within the lower extremity due to chronic hyperglycemia. The healthy human body regulates the condition of the skin by stimulating the glands to produce adequate amounts of sebum and sweat. In the body of a diabetic patient, the process of sebum secretion is disturbed, the skin becomes dry, and susceptible to damage over time. Damage to the nerves and ischemia result in losing the sensation of pain in the affected limb, so the patient does not feel the discomfort caused by cuts or abrasions, which can lead to infection of tissues at a later stage. Infection of the foot in a diabetic patient can take various forms ranging from a mild inflammation of the subcutaneous tissue to severe gangrene. In the latter case, the infection, usually of a multibacterial nature, spreads rapidly and improper management of the wound healing process leads to the formation of deep ulcers, as well as weakening of bones and joints. Approximately $15-25 \%$ of diabetics develop foot ulcers and DFS and the risk of limb amputation in diabetic patients is several times higher than in subjects without the condition [1-6]. Sample photographs of diabetic foot are presented in Figure 1.

Diabetics who are aware of their condition most often follow a diet with a low glycemic index, use appropriate medications that regulate blood glucose levels, take care of hygiene and oiling of the skin, and wear appropriate shoes. However, this is not always sufficient, in some cases, it is necessary to use appropriate dressings, antibiotic therapy, and sometimes also to remove necrotic tissue. It is estimated that up to $15 \%$ of patients may undergo a limb amputation at some stage in their lives [1-6]. Since conventional treatment of chronic wounds often fails, additional methods such as vacuum dressings, hyperbaric oxygen therapy, topical use of carbon dioxide, and other methods are used in daily practice [1-8]. 

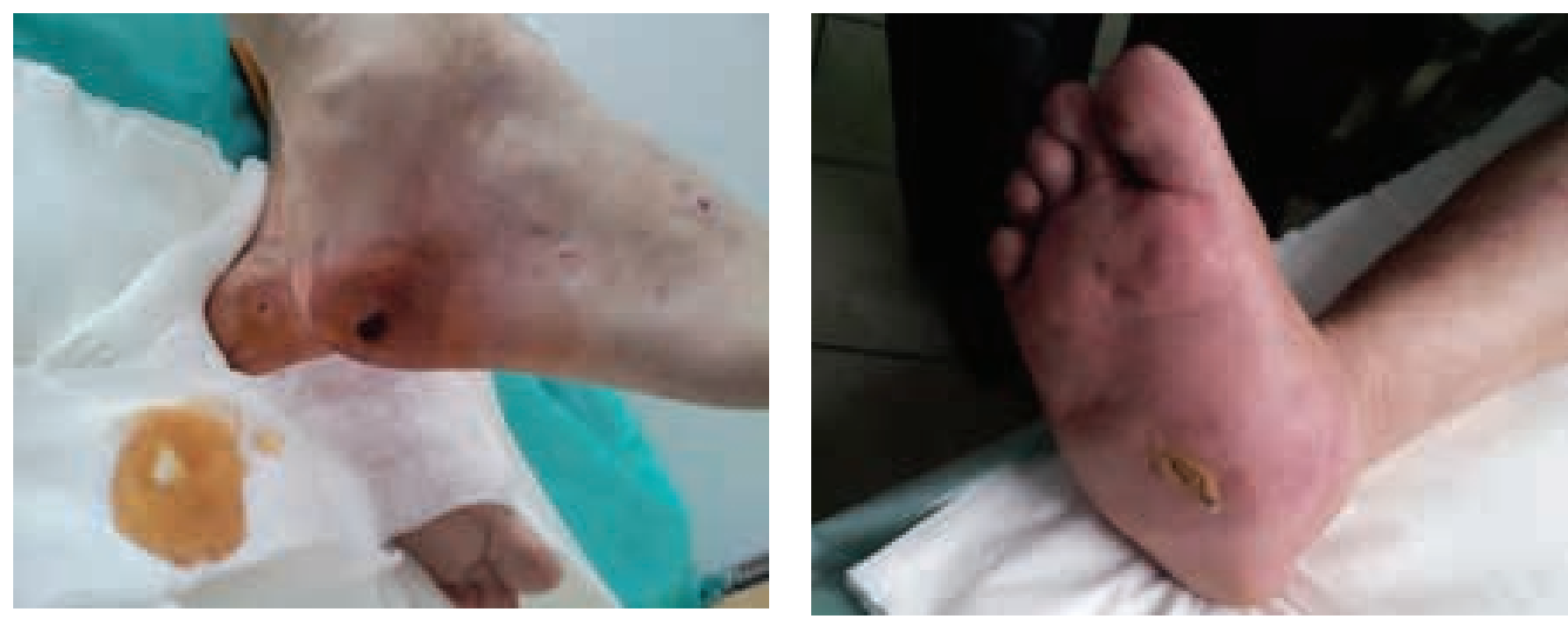

Figure 1. Feet of diabetic patients with DFS complications [7]. DFS, diabetic foot syndrome.

\section{State-of-the-art research concerning the effect of light waves in wound healing}

2.1 In vivo laboratory studies on the application of light in the treatment of slow-healing wounds in living organisms

There is ample evidence that treatment with polychromatic or monochromatic light (phototherapy), in particular infrared light and/or radiation with an energy of $<10 \mathrm{~J} / \mathrm{cm}^{2}$ and a wavelength of $600-850 \mathrm{~nm}$, promotes the repair of the skin, ligaments, tendons, bones, and cartilages in the wounds of experimental animals and ulcers of various etiology [8].

Studies by de Sousa et al. [9] using rodents evaluated the effect of irradiation with different wavelengths on the number of fibroblasts during wound healing. The red light emitted by light-emitting diode (LED; $700 \pm 20 \mathrm{~nm}, 15 \mathrm{~mW}, 10 \mathrm{~J}=\mathrm{cm}^{2}$ ) and green light emitted by LED $\left(530 \pm 20 \mathrm{~nm}, 8 \mathrm{~mW}, 10 \mathrm{~J}=\mathrm{cm}^{2}\right)$ were found to be associated with an increase in the number of fibroblasts in rodents exposed compared with the control group. The use of green and red LED lights effectively increases the proliferation of fibroblasts in rodents $[9,10]$. In a study of laboratory rats, Dungel et al. [11] showed that irradiation for $10 \mathrm{~min}$, for 5 consecutive days, with both blue $(470 \mathrm{~nm})$ and red (629 nm) LED lights can improve wound healing by improving angiogenesis. LED therapy at both wavelengths significantly increased angiogenesis in the subepidermal and muscle layers, resulting in better tissue perfusion. Tissue necrosis has been significantly reduced, and contraction much less pronounced in groups treated with LED light of both wavelengths. Treatment of tissues with LED irradiation using both wavelengths improved early wound healing [11, 12]. A study carried out in laboratory mice showed that a single exposure to low levels of red or near-infrared light significantly stimulated wound healing in the animals. Shrinking of the edges of exposed wounds within the first $24 \mathrm{~h}$ was observed as opposed to swelling of the wounds in the control group. The $820 \mathrm{~nm}$ wavelength demonstrated the best positive healing properties compared with $635 \mathrm{~nm}$, $670 \mathrm{~nm}$, and $720 \mathrm{~nm}[13,14]$.
In a study using rats with induced diabetes, $890 \mathrm{~nm}$ and $660 \mathrm{~nm}$ LED irradiation (a complex system, 32,890 nm LEDs and 4,660 $\mathrm{nm}$ LEDs, $100 \mathrm{~mW} / \mathrm{cm}^{2}$ ) were used. The wounds were irradiated for $30 \mathrm{~s}$, which resulted in the dose of $3 \mathrm{~J} /$ $\mathrm{cm}^{2}$. The combination of $660 \mathrm{~nm}$ and $890 \mathrm{~nm}$ light used in the study promoted tissue granulation and rapid healing of diabetic ulcers that had not responded to other forms of treatment [15, 16]. In diabetic rats, a light dose of $5 \mathrm{~J} / \mathrm{cm}^{2}$ and $10 \mathrm{~J} / \mathrm{cm}^{2}$ was able to alleviate the impaired healing of diabetic wounds. A group of 25 LED photons emitting 510-543 nm, 594-599 nm, 626-639 nm, 640-670 nm, and 842-872 nm wavelengths with an output power of $272 \mathrm{~mW}$ was used. The study shows that polychromatic LED therapy affects full-thickness wound healing in rats without diabetes and with diabetes. The effect of polychromatic LED therapy in full-thickness wound healing in a diabetic model using $5 \mathrm{~J} / \mathrm{cm}^{2}$ and $10 \mathrm{~J} / \mathrm{cm}^{2}$ doses has been promising $[17,18]$. In Al-Watban's rat study, different LED-emitted wavelengths $(532 \mathrm{~nm}, 633 \mathrm{~nm}, 810 \mathrm{~nm}, 980 \mathrm{~nm}$, $10,600 \mathrm{~nm}$, and $510-872 \mathrm{~nm})$ and light intensities $\left(5 \mathrm{~J} / \mathrm{cm}^{2}\right.$, $10 \mathrm{~J} / \mathrm{cm}^{2}, 20 \mathrm{~J} / \mathrm{cm}^{2}$, and $30 \mathrm{~J} / \mathrm{cm}^{2}$ ) were used. Phototherapy with a wavelength of $633 \mathrm{~nm}$ accelerated healing and showed the best therapeutic effects on diabetic wounds and burns. For the treatment of DFS, irradiations with $633 \mathrm{~nm}$ light wavelength should be performed three times a week at an intensity of $2.35 \mathrm{~J} / \mathrm{cm}^{2}[19,20]$. Santos et al. [21] irradiated wounds in mice with diabetes with wavelengths of $680 \mathrm{~nm}$ or $790 \mathrm{~nm}(2.5 \mathrm{~J} /$ $\mathrm{cm}^{2}$ ) and demonstrated an improvement in angiogenesis compared with the control group with an indication of better effects obtained with $790 \mathrm{~nm}$ [22].

\subsection{Clinical studies on the use of phototherapy in the treatment of wounds in patients with diabetic foot}

Phototherapy has also been proven to accelerate tissue repair by promoting fibroblast proliferation, synthesis of collagen, and other tissue components, and by strengthening the cellular and subcellular processes which are needed to intensify the formation of Type I and III procollagen mRNA stores, ATP synthesis, and lymphocytic activity. In diabetic patients, chronic hyperglycemia leads to uncompensated levels of metalloproteases, which degrade excessively the extracellular 
matrix, reduce the tensile strength of the skin, and delay wound healing. Phototherapy has also been demonstrated to stimulate collagen synthesis in diabetes. It is possible that phototherapy may promote the treatment of DFS by stabilizing the extracellular structural support required to facilitate wound healing in diabetic patients. The use of phototherapy may result in the stimulation of cytokines and growth factors in the wound healing process. Phototherapy stimulates the expression of proliferation, migration, survival, and healing regulators, such as primary fibroblast growth factor, interleukin and platelet growth factor, beta-transforming growth factor, and the phagocytic activity of macrophages. The recruitment of these key cytokines and growth factors is an important factor contributing to the treatment of DFS. The proliferation and differentiation of different cell lines play an important role in accelerating the treatment of DFS [23, 24].

On the overall, in vitro and in vivo studies and human clinical trials have confirmed the role of phototherapy in improvement in the healing of diabetic wounds. All the published clinical studies have shown positive results of the use of phototherapy in the treatment of DFS. In view of the lack of other effective treatment options for DFS in the published medical literature, phototherapy may become an alternative, complementary therapeutic option or a basic treatment of patients with DFS [25].

The main rationale for undertaking the studies in this area has been the complete absence of a form/action for secondary prevention that can be used in patients with Type 1 and Type 2 diabetes. The patients remain under outpatient care, involving primarily and only the control of glycemia. In addition, patients properly educated during the therapeutic process choose the appropriate footwear and socks to reduce the risk of recurrences and carry out self-monitoring of the skin condition of their feet. Despite all these elements, the risk of recurrence of active DFS (recurrence of ulcers) is very high. In as many as $15 \%$ of patients, the ultimate loss of the affected limb occurs. It should be emphasized that amputation of the extremity above the knee is associated with an $80 \%$ risk of death within 5 years after the amputation. This mortality rate is higher than that associated with the most malignant cancers (e.g., pancreatic cancer or lung cancer).

Scientific research is carried out in the leading centers in the world, especially in highly developed countries, where, based on literature reports, one can see the rationale for the effectiveness of phototherapy for hard-to-heal, extensive wounds, for different technological solutions applicable to different cases and stages of the disease.

\subsection{Lasers and LEDs for wound treatment}

In recent years, numerous studies have demonstrated the beneficial effects of low-level laser therapy (LLLT) in the treatment of various pathologies [26-38].

LLLT, also called soft laser, is known for delivering direct biostimulating light energy to the body cells. The absorbed laser energy stimulates the molecules and atoms of the cells, but does not cause a rapid or significant increase in the temperature of the tissues. While most LLLT devices illuminate the treatment area from a distance, the term LLLT also describes a new method of laser acupuncture, called a laser needle [39]. The biological action of the light wave is omnidirectional. In addition to improving peripheral nerve regeneration, reducing inflammatory reactions and improving bone formation, the role of light therapy in supporting wound healing and angiogenesis has been demonstrated [25]. Many studies have proven the effectiveness of LED phototherapy in the treatment of DFS ulcers. This method of light wave emission is safer than low-level laser emission LLLT due to the lower risk of cell damage and no temperature increase, since the LED phototherapy effect is chemical rather than thermal. The energy supplied to the cells causes slight and minimal temperature changes, usually in the range of $0.1-0.5{ }^{\circ} \mathrm{C}$. [26, 27]. This type of phototherapy provides a more superficial, even energy distribution with lower power density and longer duration of treatment than LLLT. In some clinical studies, phototherapy was performed each time for approximately 4-50 min, twice a week or twice a day, for a total of 15-90 days [23]. The effectiveness of this therapy in the case of DFS ulcers is very high. In the study by Rohringer et al. [9], three types and lengths of light waves were compared. The LED lamps for phototherapy were supplied by Repuls Lichtmedizintechnik $\mathrm{GmbH}$, Austria. LED light of wavelengths $475 \mathrm{~nm}$ (blue), $516 \mathrm{~nm}$ (green), $635 \mathrm{~nm}$ (red), or no light (control group) was used. All LED devices had a peak irradiation intensity of $80 \mathrm{~mW} / \mathrm{cm}^{2}$, which was measured with a USB 2000 spectrometer (Ocean Optics, FL, USA). Taking into account the pulse rate of $50 \%$ and the repeat frequency $=2.5 \mathrm{~Hz}$, the average irradiation intensity reached $40 \mathrm{~mW} / \mathrm{cm}^{2}$. The administered daily dose amounted to $24 \mathrm{~J} /$ $\mathrm{cm}^{2}$. Irradiation was carried out at room temperature for $10 \mathrm{~min}$ from a distance of $2 \mathrm{~cm}$. In the untreated control group, the wound area decreased by only $28.7 \% \pm 11.1 \%$ within $6 \mathrm{~h}$, in the blue light group there was a decrease of $32.0 \% \pm 9.6 \%$, in the red light group $36.6 \% \pm 6.3 \%$, and in the green light group $40.1 \% \pm 8.0 \%$; the above differences were statistically significant [25-27]. Clinical studies correlate the cellular effects and biological processes and determine the usefulness of LLLT in wound healing. In a double-blind, placebo-controlled study, the therapeutic effect of combined $660 \mathrm{~nm}$ and $890 \mathrm{~nm}$ laser treatment on 23 diabetic ulcers of the lower leg was tested during 60 days, 75 days, and 90 days of treatment by Minatela et al. The ulcers treated with placebo were cleaned, covered with $1 \%$ silver sulfadiazine cream, and treated with placebo laser irradiation $<1.0 \mathrm{~J} / \mathrm{cm}^{2}$. Within the first 30 days, their severity even worsened. Ulcers in the treatment group received the same treatment but the administered dose was $3 \mathrm{~J} / \mathrm{cm}^{2}$. On day 30 , ulcers in the treatment group achieved $56 \%$ higher granulation and $79.2 \%$ faster healing than in the placebo group, and similarly higher granulation and healing rates continued all the time. In the treatment group, 58.3\% of ulcers were healed completely and $75 \%$ achieved $90-100 \%$ healing by day 90 . In the placebo group, however, only one ulcer was completely healed and none of the ulcers healed $>90 \%$ $[39,40]$. In a clinical study, Zhou et al. [39] investigated the healing of irradiated $(633 \mathrm{~nm})$ chronic foot ulcers in 60 patients. In 28 patients, conventional therapy was used and 32 received conventional therapy plus LLLP. There were 14 patients with 
diabetes in the conventional treatment group and 18 patients with diabetes in the conventional treatment plus LLLP group. (Other causes of ulcers are not described in detail.) The ulcers were evaluated by reducing the size and immunohistochemical analysis of 70 heat shock protein (HSP70) positive cells. The expression of the protein and mRNA of heat shock factor 1 (HSF1) and HSP70 was determined by a reverse transcription polymerase chain reaction (RT-PCR). Compared with the conventional therapy group and normal skin sections, as a control group, HSF1 and HSP70 expression in the laser group was significantly higher, as it was observed in the grayscale in the Western blot bands, as well as the levels of HSF1 and HSP70 RNA in RT-PCR. Due to the laser-activated mechanism of endogenous heat shock protection in cells on the wound surface, LLLT plays a role in facilitating the healing process of chronic skin ulcers [39, 41]. Landau et al. [40] investigated the effects of visible light broadband (400-800 nm) in a double-blind, placebo-controlled, randomized study of 16 patients suffering from diabetic or non-diabetic foot ulcers. The treatment group $(n=10)$ received light irradiation of the wound twice a day at $43.2 \mathrm{~J} / \mathrm{cm}^{2}$, while the placebo group $(n=6)$ received wound light irradiation with the same device at only $2.4 \mathrm{~J} / \mathrm{cm}^{2}$, which was considered a non-therapeutic dose. All patients received conventional wound treatment. At the end of the follow-up period, all wounds in nine patients in the treatment group were closed $(90 \%)$, whereas in the placebo group only two out of six patients $(33 \%)$ had closed wounds, which were assessed according to Wagner classification for foot ulceration and based on width/length measurements. Laser therapy reduces the inflammatory response and provokes the greater proliferation of myofibroblasts in experimental skin wounds. No adverse effects of the therapy were observed [39, 42].

Clinical studies conducted in many centers confirmed the role of phototherapy in the improvement of healing of wounds of different etiology. All the published studies have demonstrated positive results of phototherapy in the treatment of patients with diabetes mellitus [23-41].

As there is a lack of effective treatment options for DFS in published medical literature, phototherapy may become an alternative, complementary therapeutic option, or a basic treatment of DFS. There are numerous scientific reasons for the use of light in the group of patients after the healing of active ulcers and in patients with diabetes mellitus and with the signs of the so-called "high risk" foot, i.e., the foot, which has characteristics that significantly increase the risk of developing DFS [1-41].

\section{Medicinal applications of optical fibers}

Fiber optics has long been used in medicine, among others, in endoscopy and laparoscopy, providing the possibility of more accurate imaging diagnostics. In addition, optical fibers are used to build flexible endoscopes equipped with a light source and an optical system called fiberscopes. Thanks to fiber optics, diagnostic tests are increasingly possible, avoiding the need for extensive tissue incisions or X-rays, which not only failed to give such clear images but were also not indifferent to the patient's health $[43,44]$.

A classic fiber optic cable is a closed structure made of glass or plastic that uses light to transmit information. In other words, a fiber optic cable is an optical fiber-a dielectric transmission medium, acting simultaneously as an electrical insulator and an optical conductor, based on fibrous technology, and its task is to transmit optical signals without loss or distortion. Fiber optics are made up of a centrally located core, a surrounding outer layer, and a protective coating (a jacket). These structures can take the form of a single fiber, a bundle of fibers, or solidified fibers (a fiber optic plate, [FOP]). Fiber optics is widely used in optotelecommunication, biomedicine, sensor technology, metrology, military systems, and classic lighting systems. The optical fibers are used as sensors to measure different values such as temperature, pressure, location, stress, and deformation, which is also well-known [43].

The fiber optic dressing mentioned in the utility model application CN208958511U [45] consists of two layers, one of which is a layer of optical fibers placed on the wound and the other is a removable layer of gauze attached with a buckle to the fiber layer. In the optical fiber layer, the fibers are arranged transversely and longitudinally, and are cross-connected into the form of a fabric mesh, so that between the fiber optics there are visible spaces in the shape of parallelograms. Lightemitting plates of cylindrical shape fixed permanently to the fiber mesh at the intersections of transverse and longitudinal fibers, projecting out of the plane of the fiber mesh, are the light sources. The dressing also contains a light-collecting plate. This dressing is cumbersome to use due to the use of a buckle connecting its layers, as well as the use of light sources protruding from the dressing surface. There is no information in the document on the type of light used, as well as on the presence of sensors in the dressing to monitor the condition of the tissue, which means that the use of this dressing for a specific purpose must be preceded by a series of tests and experiments.

The description of the patent application WO2020/064937 A1 [46] reveals a two-layer fiber optic dressing, the fiber layer of which placed on the wound is one or more optical fiber systems in the form of a mesh or a zig-zag, superimposed on top of each other, and the top layer is a replaceable layer of gauze, spacer knit, etc. Optical fibers emit a light wave only at the ends of the fibers or from holes drilled in them. Although the document indicates the light wavelength range used was 300$2,000 \mathrm{~nm}$, there is no information about how the light wave was used for treatment and how it had been achieved or how to achieve, suggesting that the fiber optics act only as sensors to detect the properties of the wound. The dressing may have in its structure, in addition to the fiber optic mesh, additional diagnostic factors, in the form of $\mathrm{pH}$ or thermochromic strips reacting to heat emitted from the wound and suggesting inflammation signaled by higher temperature, but these are ad hoc and disposable solutions. 


\section{Knitted optical fiber dressing using fiber optic and laser technology_conceptual testing}

To meet the expectations of patients with DFS and to improve the quality of life of diabetic patients, a dressing device was developed by the authors of this publication. Such a dressing will meet several requirements, the most important of them are high therapeutic efficacy, simple application, and user safety. Therefore, it was decided to combine a knitted product with optical fibers emitting a specific light wavelength along its entire surface, which will be powered by a semiconductor laser. Scientists have already proposed ways to combine fiber optics with knits, although these products were not designed for medicinal use [47-51, 43, 52].

A rarely used type of optical fiber, a lateral propagation optical fiber, was used for research purposes. It is a so-called light diffuser fiber and is most often produced by mechanical incision of the fiber so that a beam dispersion can be obtained. The appearance of a lateral propagation optical fiber is shown in Figure 2.

The solution of a textile diagnostic and therapeutic dressing for wounds of patients with DFS uses light of a specific wavelength to accelerate the treatment and diagnosis of foot wounds. The textile dressing, intended for management of DFS wounds, has optical fibers coupled in a disconnectable manner with a light source, including diagnostic elements, is a singlelayer device and constitutes a knitted layer made of natural mineral fibers, synthetic fibers, man-made fibers, and others, containing transparent gradient optical fibers emitting light from the lateral surface, placed in the entire structure or a part of its structure, in the form of mesh eyes or weft, introduced in the process of knitting. As a light source, the dressing contains a semiconductor laser or an electroluminescent diode, emitting a light wave of a specific length. The dressing may contain flat-shaped temperature and humidity sensors designed to monitor the condition of the foot skin, attached to the knitted layer on the wound side, coupled with a device for recording and displaying the temperature data. A semiconductor laser or an electroluminescent electrode emitting light waves within the $400-1,200 \mathrm{~nm}$ range is used. The $400-500 \mathrm{~nm}$ wavelength light is designed to activate anti-inflammatory processes and to exert antiseptic and bactericidal effects on the wound; the $570-590 \mathrm{~nm}$ wavelength is intended to relieve the skin irritation, improve the lymph flow, boost the body's protective system, and stimulate collagen production; the 630-700 nm wavelength is used to improve the blood supply, stimulate the metabolism of skin cells, and accelerate wound healing; the $520-540 \mathrm{~nm}$ wavelength is used to control discoloration and reduce swelling; and the $800-1,200 \mathrm{~nm}$ wavelength is used to accelerate wound healing and support the treatment of ulcerations. The dressing is a layer of flat knitted fabric. The time of the phototherapy procedure and the type of light emitted on the diseased foot is selected by the attending physician based on the anamnesis and medical history. The dressing can emit a light wave on the entire contact surface, or a fragment of it, which is achieved by personalizing the dressing, as directed by the attending physician. The patient can use it himself at home. It performs both the function of accelerating wound healing and the functions of monitoring the condition of the wound. The schematic diagram of the dressing is shown in Figure 3.

It was decided to supply the incorporated fiber optics with a $405 \mathrm{~nm}$ light wave since it has bactericidal and regenerative properties, penetrates only through the epidermis and stops in the structure of the dermis (radiation penetration depth not exceeding $1 \mathrm{~mm}$ ), which limits the development of microbes and promotes the healing process of diabetic foot wounds.

In future research, the authors intend to power the fiber optics with other light parameters. Differences in the penetration of light radiation of different wavelengths through the tissues are presented in Figure 4.

The intensity of radiation, which will be administered to the patient as well as the area exposed to irradiation, is also very important in the case of phototherapy of diabetic foot. The dressing may emit light over the entire contact surface of the device, or over a part of it (e.g., a light wave may be emitted by a $5 \mathrm{~cm}^{2}$ area), which will be achieved by personalization of the dressing, or developing an appropriate shape of the lightemitting element selected for the patient, as recommended by the attending physician.

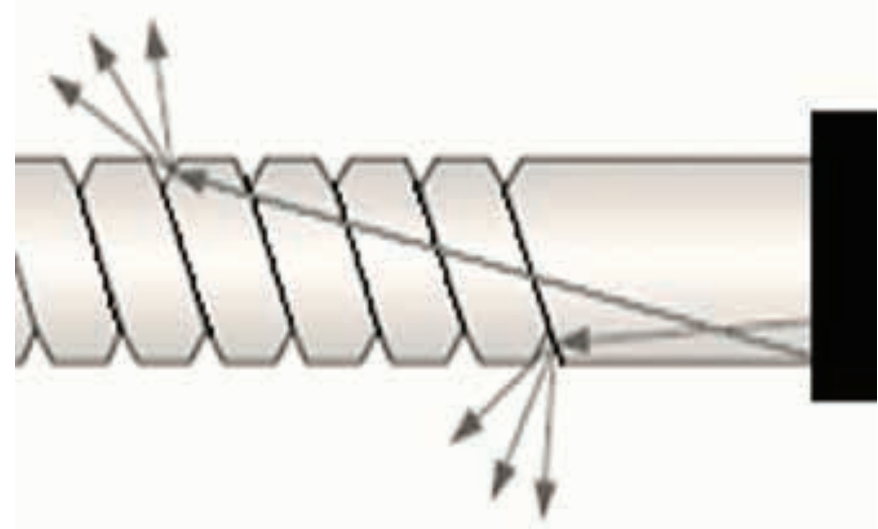

Figure 2. A lateral propagation optical fiber.

\section{1}

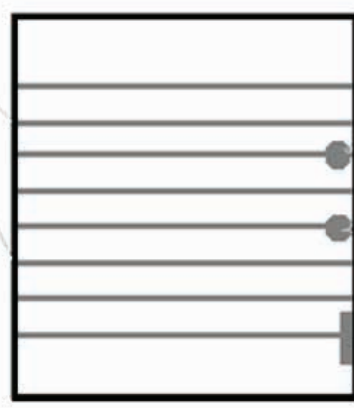

Figure 3. 1-optical fibers or LEDs, 2-light source, 3-sensors, 4-recording device. LED, light-emitting diode. 


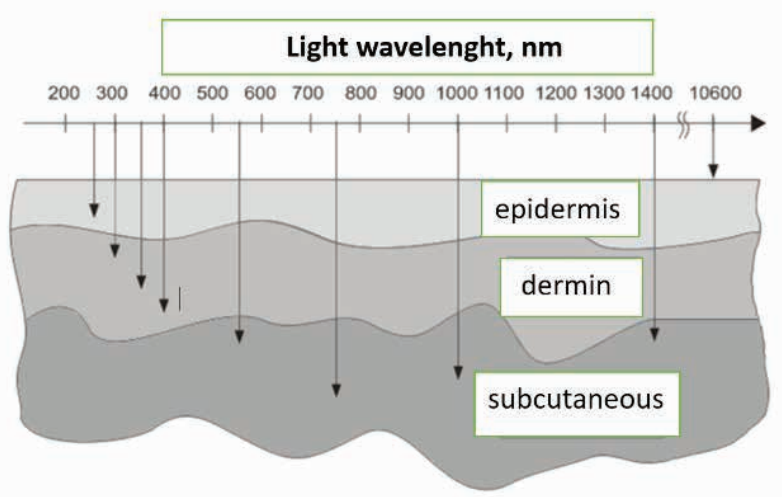

Figure 4. Differences in the depth of energy penetration through the skin depending on the radiation wavelength [51].

\section{Knitted optical fiber dressing technology}

A dressing product measuring $100 \mathrm{~mm} \times 300 \mathrm{~mm}$, in the form of a row knitted fabric with a double-right weave, was made on a double-bearing flat crochet machine with needle number 3.5. Polyester yarn of 210 tex linear weight and lateral propagation optical fibers with an external diameter of $0.75 \mathrm{~mm}$ made of poly(methyl methacrylate), PMMA, were used to manufacture the dressing, As a result, a textile dressing of $473 \mathrm{~g} / \mathrm{m}^{2}$ surface mass and $0.43 \mathrm{~mm}$ thickness was obtained. The wale density of the knitted fabric was 51 with the course density 45 . Figure 5 shows the scheme of the manufactured product and the positive effects of light emission in the context of compositeknitted dressing with fiber optics emitting laser light of a specific wavelength.

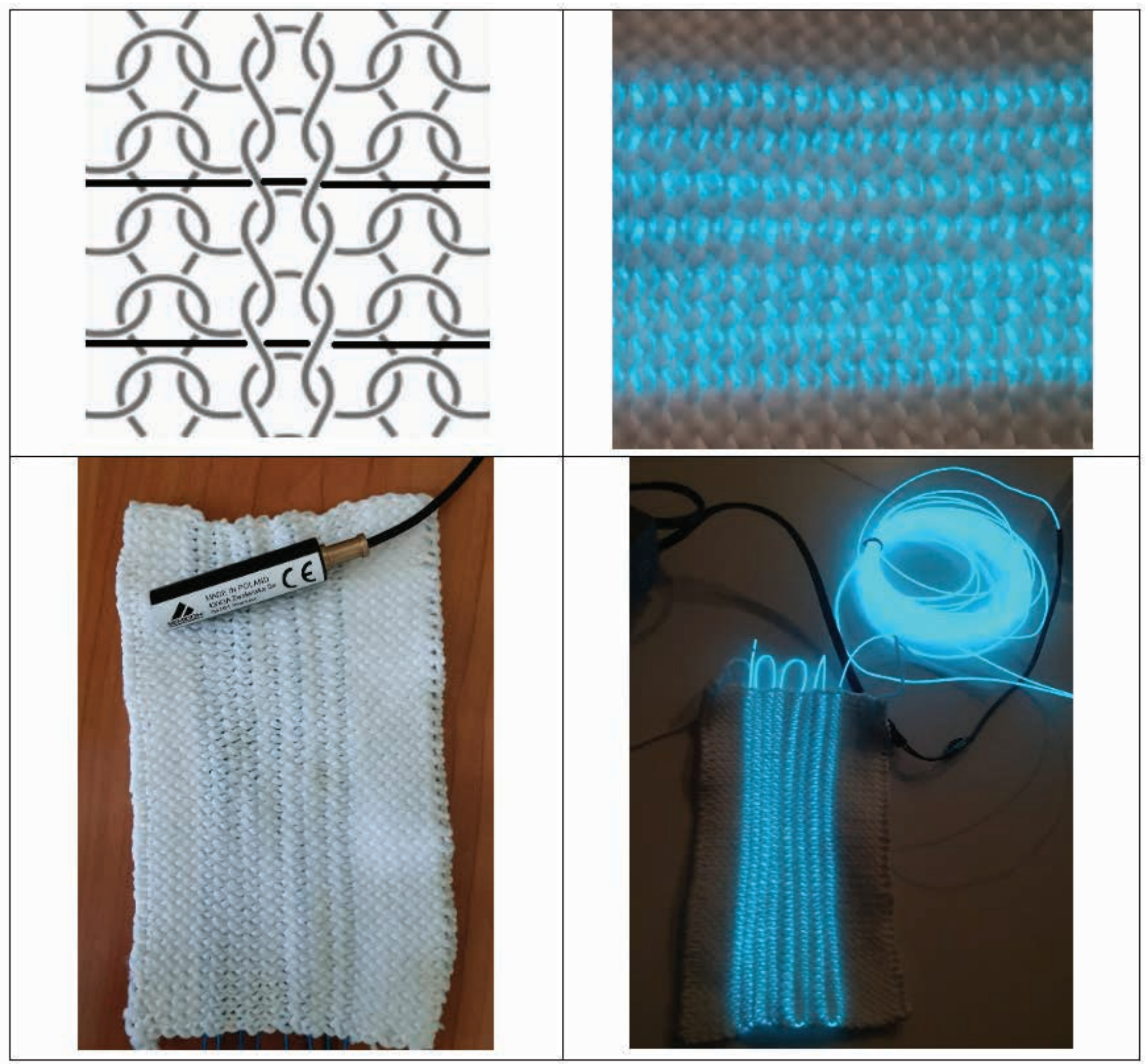

Figure 5. Structure of knitted fabric with fiber optics and photograph of the photo-dressing produced. 
Table 1. Technical parameters of the Semicon laser.

\begin{tabular}{|c|c|}
\hline Safety class & 3R acc. to PN-EN 60825-1:2014 \\
\hline Wavelength & $\Lambda=405 \mathrm{~nm} \pm 10 \mathrm{~nm}$ \\
\hline Optical power & $5 \mathrm{~mW} \pm 0.5 \mathrm{~mW}$ \\
\hline Power supply & AC adapter 230V AC/3.5VDC/150 mA with LEMO connector \\
\hline Power consumption & $<100 \mathrm{~mA}$ \\
\hline Laser output beam diameter & $4.5 \mathrm{~mm} \pm 05 \mathrm{~mm}$ \\
\hline Beam divergence & $<1.5 \mathrm{mrad}$ \\
\hline Factory set Focus distance & Infinity \\
\hline
\end{tabular}

The optical fibers were powered by a $405 \mathrm{~nm}$ light wave using a Semicon ML-27P-405-5 universal industrial module. The laser parameters are presented in Table 1.

The research on the development of knitted fabric structures with incorporated light-emitting elements is still ongoing and the result is a patent application number P.434454.

\section{Summary}

1. Diabetes is the most common health problem in modern society and the number of people suffering from this condition is increasing dramatically every year. It is estimated that $>422$ million people worldwide are affected and this is an extremely important medical, social, and economic problem. If left untreated, or poorly treated, diabetes carries a risk of several complications, including DFS. Infection of the foot can take various forms ranging from a mild inflammation of the subcutaneous tissue to severe gangrene. Since pharmacological or surgical treatment of chronic wounds often does not produce the desired results, additional methods such as vacuum dressings, hyperbaric oxygen therapy, topical use of carbon dioxide, and others, including phototherapy, are used in practice.

2. In vivo laboratory studies on the use of light in the management of hard-to-treat wounds in living organisms demonstrate that treatment with polychromatic or monochromatic light (phototherapy), in particular, infrared light and/or infrared radiation of 600-850 nm wavelength, promotes rapid healing of diabetic ulcers that have not responded to other forms of treatment. In rodents with diabetes, a light dose of $5 \mathrm{~J} / \mathrm{cm}^{2}$ and $10 \mathrm{~J} / \mathrm{cm}^{2}$ was able to alleviate the impaired healing of diabetic wounds.

3. Clinical studies on the use of phototherapy in the treatment of wounds in patients with DFS show that phototherapy accelerates tissue repair by promoting the proliferation of fibroblasts, the synthesis of collagen and other tissue components, and by boosting the cellular and subcellular processes that are needed to intensify the formation of Type I and III procollagen mRNA stores, ATP synthesis, and lymphocytic activity. Phototherapy can promote the treatment of DFS by stabilizing extracellular structural support and by stimulating cytokines and growth factors to support wound healing. All the published clinical studies have demonstrated positive results of phototherapy in the treatment of DFS.

4. In recent years, numerous clinical studies have indicated the beneficial effects of LLLT and the use of LED in the treatment of various pathologies, including the treatment of DSF ulcers. As there is a lack of effective treatment options for DSF in the published medical literature, phototherapy may become an alternative, complementary therapeutic option or the basic method of treatment. There are a lot of scientific reasons for the use of light in the group of patients after healing of active ulcers as well as in patients with diabetes mellitus and with the signs of the so-called "high risk" foot.

5. Knitted optical fiber dressing was achieved with the advantage of the fiber optic technology, and further a laser was developed by the authors of this publicationresearch workers from the Technical University of Lodz and the Medical University of Lodz for this application. It was decided to combine a knitted product with optical fibers emitting a specific wavelength of light on its entire surface, which are powered by a semiconductor laser. The textile dressing contains also diagnostic elements in the form of temperature and humidity sensors. Within the framework of the study, a prototype dressing of $100 \mathrm{~mm} \square 300 \mathrm{~mm}$ was produced in the form of a double-right row-knitted fabric made of polyester threads and lateral propagation optical fibers of $0.75 \mathrm{~mm}$ external diameter, made of poly(methyl methacrylate). The optical fibers were powered by a $405 \mathrm{~nm}$ light wavelength. Research into the development of knitted structures with incorporated lightemitting elements is still ongoing, and the result of this work is a patent application number P.434454.

\section{References}

[1] Główny Urząd Statystyczny/Infografiki, widżety/Infografiki/ Infografika - Cukier w Polsce. Retrieved June 25, 2021. Web site: https://stat.gov.pl/infografiki-widzety/infografiki/ infografika-swiatowy-dzien-walki-z-cukrzyca-14listopada, 46, 3.html 
[2] Global report on diabetes. Retrieved June 25, 2021. Web site: https://www.who.int/publications/i/item/9789241565257.

[3] Małecki, R., Rosiński, K., Adamiec, R. (2014). Etiological factors of infections in diabetic foot syndrome - Attempt to define optimal empirical therapy. Advances in Clinical Experimental Medicine, 23(1), 39-48.

[4] Lipsky, B. (2004). A report from the international consensus on diagnosing and treating the infected diabetic foot. Diabetes Metabolism Research and Reviews, 20, 68-77.

[5] Emilia, R., Sołdaj-Bukszyńska, K., Kowalik, M., Lis, B., Dzida, G. (2017). Diabetic foot syndrome as an interdisciplinary problem. Journal of Education, Health and Sport, 7(8), 576-582, eISSN 2391-8306.

[6] Formosa, C., Cassar, K., Gatt, A., Mizzi, A., Mizzi, S., et al. (2013). Hidden dangers revealed by misdiagnosed peripheral arterial disease using ABPI measurement. Diabetes Research and Clinical Practice, 102(2), 112-116.

[7] Popławska-Kita, A. (2016). Dermatologia geriatryczna. T. 2. Pod red. Andrzeja Kaszuby, Jacka Szepietowskiego, Zygmunta Adamskiego, rozdział w książce, strony, 329343.

[8] Wang, H. T., Yuan, J. Q., Zhang, B., Dong, M. L., Mao, C., et al. (2017). Phototherapy for treating foot ulcers in people with diabetes. Cochrane Database of Systematic Reviews, 6. John Wiley and Sons Ltd, Jun. 28, 2017, doi: 10.1002/14651858.CD011979.pub2.

[9] de Sousa, A. P. C., Santos, J. N., dos Reis, J. A., Ramos, T. A., de Souza, J., et al. (2010). Effect of LED phototherapy of three distinct wavelengths on fibroblasts on wound healing: A histological study in a rodent model. Photomedicine and Laser Surgery, 28(4), 547-552. doi: 10.1089/pho.2009.2605

[10] Al-Watban, F.A.H., Andres, B.L. (2003). PolychromaticLED therapy in burn healing of non-diabetic and diabetic rats. Journal of Clinical Laser Medicine \& Surgery, 21, 249-252.

[11] Dungel, P., Hartinger, J., Chaudary, S., Slezak, P., Hofmann, $A$., et al. (2014). Low level light therapy by LED of different wavelength induces angiogenesis and improves ischemic wound healing. Lasers in Surgery and Medicine, 46(10), 773-780. doi: 10.1002/lsm.22299.

[12] Al-Watban, F.A.H., Delgado, G.D. (2005). Burn healing with a diode laser: $670 \mathrm{~nm}$ at different doses as compared to a placebo group. Photomedicine and Laser Surgery, 23, 245-250

[13] Demidova-Rice, T. N., Salomatina, E. V., Yaroslavsky, A. N., Herman, I. M., Hamblin, M. R. (2007). Low-level light stimulates excisional wound healing in mice. Lasers in Surgery and Medicine, 39(9), 706-715. doi: 10.1002/ Ism. 20549.

[14] Karu, T. I., Kolyakov, S. F. (2005). Exact action spectra for cellular responses relevant to phototherapy. Photomedicine and Laser Surgery, 2005;23(4):355-361.

[15] Minatel, D. G., Frade, M. A. C., França, S. C., Enwemeka, C. S. (2009). Phototherapy promotes healing of chronic diabetic leg ulcers that failed to respond to other therapies. Lasers in Surgery and Medicine, 41(6), 433-441. doi: 10.1002/lsm.20789.

[16] DeLellis, S. L., Carnegie, D. H., Burke, T. J. (2005). Improved sensitivity in patients with peripheral neuropathy. Effects of monochromatic infrared photo energy. Journal of the American Podiatric Medical Association, 2005;95:143147.
[17] Al-Watban, F. A. H., Andres, B. L. (2006). Polychromatic LED in Oval Full-Thickness Wound Healing in Non-diabetic and Diabetic Rats. Photomedicine and Laser Surgery, 24(1), 10-16. doi: 10.1089/pho.2006.24.10.

[18] Lee, P., Kim, K., Kim, K. (1993). Effects of low incident energy levels of infrared laser irradiation on healing of infected open skin wounds in rats. Laser Therapy, 5, 5964.

[19] Al-Watban, F. A. H. (2009). Laser therapy converts diabetic wound healing to normal healing. Photomedicine and Laser Surgery, 27(1), 127-135.

[20] Mendez, T. M., Pinheiro, A. L., Pacheco, M. T., Nascimento, P. M., Ramalho, L. M. (2004). Dose and wavelength of laser light have influence on the repair of cutaneous wounds. Journal of Clinical Laser Medicine \& Surgery, 22, 19-25.

[21] Santos, N. R. S., Dos Santos, J. N., Dos Reis, J. A., Oliveira, P. C., de Sousa, A. P. C., et al. (2010). Influence

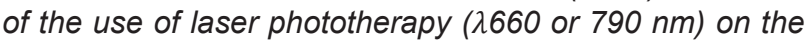
survival of cutaneous flaps on diabetic rats. Photomedicine and Laser Surgery, 28(4), 483-488.

[22] Caetano, K. S., Frade, M. A. C., Minatel. D. G., Santana, L. A., Enwemeka. C. S. (2009). Phototherapy improves healing of chronic venous ulcers. Photomedicine and Laser Surgery, 27, 111-118.

[23] Rohringer, S., Holnthoner, W., Chaudary, S., Slezak, P., Priglinger, E., et al. (2017). The impact of wavelengths of LED light-therapy on endothelial cells. Scientific Reports, 7(1), 1-11, doi: 10.1038/s41598-017-11061-y.

[24] Chaves, M. E. A., Piancastelli A. C. C., de Araújo A. R., Pinotti $M$. (2014). Effects of low-power light therapy on wound healing: LASER x LED. Anais Brasileiros de Dermatologia, 89(4). Sociedade Brasileira de Dermatologia, 616-623. doi: 10.1590/abd1806-4841.20142519.

[25] MedX Health. About phototherapy. Web site: www. medxhealth.com/Our-Products/Phototherapy/overview. aspx (accessed 27 May 2016). - Szukaj w Google. https:// www.google.com/search?q=MedX+Health. + About + pho totherapy. + www.medxhealth.com\% 2 FOurProducts $\% 2 F$ Phototherapy\%2Foverview. asp + (accessed $+27+$ May + 2016). \&oq=MedX+Health. + About + phototherapy. + www. medxhealth.com\%2FOurProducts\%2FPhototherapy $\% 2 F$ overview. aspx+(accessed+27+May+2016). \&aqs=chrom e..69i57.479j0j4\&sourceid=chrome\&ie=UTF-8 (accessed June 25, 2021).

[26] El-Deen, H. B., Fahmy, S., Ali, S. A., El-Sayed, W. M. (2014). Polarized light versus light-emitting diode on healing of chronic diabetic foot ulcer. Romanian Journal of Biophysics, 24(2):1-15.

[27] Beckmann, K. H., Meyer-Hamme, G., Schröder, S. (2014). Low level laser therapy for the treatment of diabetic foot ulcers: A critical survey, Hindawi Publishing Corporation Evidence-Based Complementary and Alternative Medicine, Article ID 626127. doi: 10.1155/2014/626127.

[28] Al-Watban, F. A. H., Andres, B. L. (2008). Low power laser therapy for wound and burn healing. Laser Medicine Feature-Arab Health Magazine, 3, 48-51.

[29] Al-Watban, F. A. H., Zhang, X. Y., Andres, B. L. (2007). Low level laser therapy enhances wound healing in diabetic rats: A comparison of different lasers. Photomedicine and Laser Surgery, 25, 72-77. 
[30] Bayat, M., Vasheghani, M. M., Razavi, N., Taheri, S., Rakhshan, M. (2005). Effect of low-level laser therapy on the healing of second-degree burns in rats: a histological and microbiological study. Journal of Photochemistry and Photobiology B: Biology, 78, 171-177.

[31] Gaida, K., Koller, R., Isler, C., et al. (2004). Low level laser therapy - A conservative approach to the burn scar? Burns, 30, 362-367.

[32] Sommer, A. P., Pinheiro, A. L. B., Mester, A. R., Franke, R. P., Whelan, H. T. (2001). Biostimulatory windows in low intensity laser activation: Lasers, scanners and nasa's light-emitting diode array system. Journal of Clinical Laser Medicine \& Surgery, 19, 29-34.

[33] Webb, C., Dyson, M. (2003). The effect of $880 \mathrm{~nm}$ low level laser energy on human fibroblast cell numbers: $A$ possible role in hypertrophic wound healing. Journal of Photochemistry and Photobiology B: Biology, 70:39-44.

[34] Ribeiro, M. S., da Silva, D. F., de Araujo. C E., De Oliveira, S. F., Pelegrini, C. M. R., et al. (2004). Effects of lowintensity polarized visible laser radiation on skin burns: a light microscopy study. Journal of Clinical Laser Medicine \& Surgery, 22, 59-66.

[35] Herascu, N., Velciu, B., Calin, M., Savastru, D., Talianu, C. (2005). Low-level laser therapy (LLLT) efficacy in postoperative wounds. Photomedicine and Laser Surgery, 23, 70-73.

[36] Wong-Riley, M. T. T., Bai, X., Buchmann, E., Whelan, H. T. (2001). Light-emitting diode treatment reverses the effect of TTX on cytochrome oxidase in neurons. NeuroReport, 12, 3033-3037.

[37] Schindl, A., Schindl, M., Scho"n, H., Knobler, R., Havelec, L., Schindl, L. (1998). Low-intensity laser irradiation improves skin circulation in patients with diabetic microangiopathy. Diabetes Care, 21, 580-584.

[38] Minatel, D. G., Frade, M. A. C., França, S. C., Enwemeka, C. S. (2009). Phototherapy promotes healing of chronic diabetic leg ulcers that failed to respond to other therapies. Lasers in Surgery and Medicine, 41(6), 433-441.

[39] Zhou, J.-D., Luo, C.-Q., Xieetal, H.-Q. (2008). Increasedexpressionofheart shock protein 70 and heat shock factor 1 in chronic dermalulcer tissues treated with laser-aided therapy. Chinese Medical Journal, 121(14), 1269-1273.
[40] Landau, Z., Migdal, M., Lipovsky, A., Lubart, R. (2011). Visible light-induced healing of diabetic or venous foot ulcers:a placebo-controlled double-blind study. Photomedicine and Laser Surgery, 29(6), 399-404.

[41] Romaniuk, R., Romaniuk, I. (1983). Światłowody w medycynie. PROBLEMY. 1983, 17-20. Ryszard Romaniuk, Irena U. Romaniuk, Światłowody w medycynie; PROBLEMY, Miesięcznik popularnonaukowy, nr 07, 1984.

[42] Gryko, Ł., Zajac, A. J. (2016). Wykorzystanie diod LED w medycynie (The use of LEDs in medicine).

[43] Sekhejane, P. R., Houreld, N. N., Abrahamse, H. (2011). Irradiation at $636 \mathrm{~nm}$ positively affects diabetic wounded and hypoxic cells in vitro. Photomedicine and Laser Surgery, 29(8), 521-530.

[44] Patent application CN208958511U LIGHT dressing.

[45] Patent application WO2020/064937 A1 Optical fibers for optically sensing through wound dressings.

[46] Quandt, B. M., Pfister, M. S., Lubben, J. F., Spano, F., Rossi, R. M., et al. (2017). POF-yarn weaves: controlling the light out-coupling of wearable phototherapy devices. Biomedical Optics Express, 8, 4316-4330.

[47] Zeng, W. (2015). Polymer optical fiber for smart textiles. In: Tao, X. (Ed.). Handbook of smart textiles. Springer Singapore (Singapore). pp. 109-125.

[48] Kumar, L. A. (2013). Vigneswaran: Electronics in textile and clothing. Design, Products and Application, ISBN-13 : 978-1498715508.

[49] Hilly, S. M.. Al-Khalee, Z. E. L., Alrubaye, A. F. (2011). Fiber optic sensor for measuring rotation, Al-Nahrain Journal of Science, 14(4), 66-72.

[50] Łada-Tondyra, E., Jakubas, A. (2018). Nowoczesne zastosowania systemów tekstronicznych. Przegląd Elektrotechniczny, ISSN 0033-2097, R. 94 NR 12/2018.

[51] Nowak, I. (2022). Innovative knitted fabrics containing lateral propagation optical fibers designed for children with autism - Preliminary Study. Fibers and Textile in Easter Europe.

[52] Cysewska-Sobusiak, A.. Prokop, D., Jukiewicz, M., Tendencje Rozwojowe, I. (2009). Obszary Zastosowań Technik Światłowodowych, Poznań University of Technology, Academic Heimdal E.J., Flat knitting of a light emitting textile with optical fibers. Autex Research Journal, 9(2), 61-65. 